\title{
Interview
}

\section{Music to Our Ears: Interview with Victoria Williamson}

\author{
Rhian Worth ${ }^{\star a}$, Victoria Williamson ${ }^{b}$ \\ a Bangor University, Bangor, UK. 'Department of Psychology, Goldsmiths, University of London, London, UK.
}

Rhian Worth: How did you start working on memory?

Victoria Williamson: My interest in memory began when I was a psychology undergraduate at the University of York (UK). In my third year I attended a module called 'Practical Applications of the Psychology of Memory', which was taught by Profs. Alan Baddeley and Graham Hitch. I was fascinated right from the start. The course focused equally on expert memory and memory disorders, and built on the basic understanding of memory cognition that we had built up in our first two years of the psychology degree. I was surprised and heartened by the patient studies as well as being intrigued by the possibilities seen in expert memory performance.

My interest in memory continued after I began a Masters degree in the Psychology of Music (MA) at the University of Sheffield. I was keen to learn more about how professional musicians learn to use their memory and began to be intrigued by the question of whether they developed specialised memory systems as a result of their extreme training.

While at Sheffield I had a lecture on music and short-term memory by Prof. Eric Clarke (currently at Oxford). He presented a diagram from a publication by Berz (1995) which postulated an additional loop within the working memory model - a musical loop. I took this image back to York to show to Alan Baddeley and I remember his reaction quite clearly. He smiled, looked at me and said 'looks like a good idea for a PhD if you are interested'. I was. I applied and was accepted for a PhD to study the role of music in the working memory model.

Rhian Worth: What projects have you been involved with in the past and what kinds of findings have you had?

Victoria Williamson: For my PhD work I chose to study the working memory model as an empirical framework and adapted traditional short-term verbal memory paradigms to the musical domain in order to compare processing of verbal and tonal sequences. I built a new type of serial recall paradigm for musical and verbal sounds that can be used by musicians and non-musicians, which we called the recall matrix. We used the matrix to compare 
immediate serial recall of verbal and tonal sequences under conditions of phonological similarity (and its musical equivalent, pitch proximity) (Williamson, Baddeley, \& Hitch, 2010a), articulatory suppression and irrelevant sound.

To summarise the outcome of all the findings, I postulated that there was likely to be strong overlap in the subvocal rehearsal processing that was necessary to refresh both verbal and tonal sounds in memory but more distinct storage mechanisms, especially in musicians. This theory has found support from recent neuroimaging work by Katrin Schulze (Schulze, Mueller, \& Koelsch, 2011a; Schulze, Zysset, Mueller, Friederici, \& Koelsch, 2011b)

After I finished my PhD I began a postdoctoral fellowship investigating short-term memory ability in individuals with congenital amusia (tone deafness). I found that these special individuals had increased decay in their short-term memory for single absolute pitch sounds compared to matched controls (Williamson et al., 2010b) and significantly smaller tone sequence spans (but comparable verbal sequence spans; Williamson \& Stewart, 2010 and visuo-spatial memory; Williamson, Cocchini, \& Stewart, 2011). In short, these individuals appear to exhibit a tone specific memory difficulty.

Rhian Worth: What are you working on at the moment?

Victoria Williamson: At the moment I am working on an interesting form of involuntary memory that is specific to musical imagery: we call them 'earworms'. An earworm (or Involuntary Musical Imagery) is a short snippet of music that comes unbidden into the mind and then repeats outside the will of conscious control. Not much work has been done on this phenomenon apart from questionnaire studies that have established its prevalence in everyday life (e.g. Beaman \& Williams, 2010; Halpern \& Bartlett, 2011; Liikkanen, 2012). We have been collecting thousands of earworm stories in collaboration with the $\mathrm{BBC}$, and the radio station 6Music in particular.

Our initial analysis has documented the situational antecedents of earworms and revealed an important role for general involuntary memory processes in the experience (Williamson et al., 2012). At the time of writing

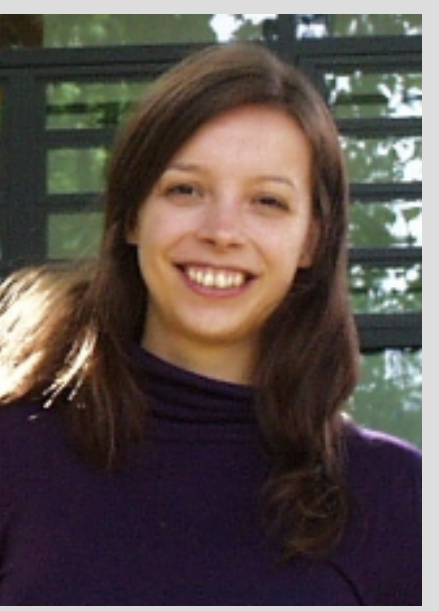

Victoria Williamson is a lecture and co-director on the Msc in Music, Mind and Brain at Goldsmiths, University of London. Following completing her $\mathrm{PhD}$ with Professors Alan Baddeley and Graham Hitch at University of York looking at the role of music in the working memory model, Victoria was awarded an ESRC Fellowship and moved to Goldmiths, University of London. Victoria's current research includes the fascinating earworm project, whilst previous research has included looking at congenital amusia, and music and driving. In this interview Victoria discusses past and present research, main directions in current research and an insight into Victoria's sources of inspiration in her career.

Correspondence: Victoria Williamson, Department of Psychology, Goldsmiths, University of London, New Cross, London, SE14 6NW.

Email:v.williamson@gold.ac.uk we are completing two further studies that explore the links between individual differences and earworm characteristics (frequency, length and control) and the musical structure of earworm tunes as compared to matched control tunes.

Rhian Worth: What do you hope these findings will achieve and/or practical application of the findings?

Victoria Williamson: Earworms are so ubiquitous and prevalent in everyday life that I believe there is real practical application in understanding more about their aetiology and how we might control them. Thinking a little wider 
however, there are also interesting potential applications for learning. Wouldn't it be great if we could recall useful knowledge as easily as an earworm! I hope that by learning more about why and how these tunes get stuck in our heads we can extrapolate information that will help us build learning materials that are more easily encoded and/or recalled. This is nothing new in theory of course; I still recall with ease the song I was taught in order to learn my alphabet. But there is big potential to improve understanding of this practice once we have a more systematic understanding of why tunes come so easily to mind.

Rhian Worth: You recently spoke on the BBC about some of your work: how important is it to be able to talk your work like this in terms of research and findings?

Victoria Williamson: I have benefited hugely from my interactions with the media, which you can see by visiting my educational blog at musicpsychology.co.uk. Journalists are extremely busy people of course, but they have also been very helpful to me in terms of gathering data and disseminating the results of our work. I received some very useful free training in media interaction from the Science Media Centre in London and I would recommend that any early career researcher invests time in similar professional development activities. Both the traditional media and digital/social media can add a whole new dimension to research, as they give you a direct line to the general public.

Rhian Worth: What is your opinion about the state of affairs in the psychology of memory and current research: what are the main directions?

Victoria Williamson: The psychology of memory is such a critically important field and one that contributes in numerous ways to other new and emerging fields, including music psychology. I am glad that students are still taught about the history of the discipline as I think this factor is crucial to understanding how and why we have come to the present state of affairs in memory research. And although neuroscience has provided fascinating insights I am glad that memory is still one of the fields of psychology that is strongly anchored in the traditional of behavioural work.

Of all the future directions, I am personally most excited by involuntary memory phenomena, including recent interest in involuntary autobiographical memory (Berntsen, 2009) and semantic memory (Kvavilashvili \& Mandler, 2004), which has followed on from research into mind wandering and the activity of the 'resting state brain'. I think there will be many new interesting insights to come from this area in the next few years.

Rhian Worth: Is there any advice you would have for people who want to study memory, memory and music and teach memory?

Victoria Williamson: Number one, read the classic literature. Follow the trail of how research in your field of memory developed when you first begin a project, in order to give you the best understanding of where you could or should go in the future.

If you want to study music and memory, then my best advice is talk to musicians. Their descriptions of their memory techniques are fascinating and have no doubt inspired a great deal of research in the past. My second piece of advice is to tread carefully. Years ago I had the idea it would be fairly straight forward to adapt classic verbal short-term memory tests to musical stimuli, but there were so many different variables that I had to consider, that in the end it took nearly a year to come up with a decent design. Music is not a language, and it is a mistake to treat it as just a series of notes in the same way that one can treat verbal material as a sequence of consonants. 
Teaching memory must be one of the most fun jobs in the business. There are so many great examples that you can use; case studies, patient histories and real world applications. Give your lessons relevance and impact by placing memory in the context of everyday life.

Rhian Worth: Who has been a source of inspiration for you this far in your career?

Victoria Williamson: I have found many sources of inspiration from the wonderful colleagues that I have studied alongside and worked with over the past few years. When you work in an interdisciplinary context there is an even wider scope to learn from individuals who come from very different academic worlds. My current research manager, Dr Lauren Stewart, is my guiding light as I navigate the choppy waters of early career research. But without a doubt, my main career inspirations were, and always will be, Professors Alan Baddeley and Graham Hitch.

\section{References}

Beaman, C. P., \& Williams, T. I. (2010). Earworms (stuck song syndrome): Towards a natural history of intrusive thoughts. British Journal of Psychology, 101(4), 637-653. doi:10.1348/000712609X479636

Berntsen, D. (2009). Involuntary autobiographical memories: An introduction to the unbidden past. Cambridge, England: Cambridge University Press.

Berz, W. L. (1995). Working memory in music: A theoretical model. Music Perception, 12(3), 353-364.

Halpern, A. R., \& Bartlett, J. C. (2011). The persistence of musical memories: A descriptive study of earworms. Music Perception, 28, 425-432. doi:10.1525/mp.2011.28.4.425

Kvavilashvili, L., \& Mandler, G. (2004). Out of one's mind: A study of involuntary semantic memories. Cognitive Psychology, 48, 47-94. doi:10.1016/S0010-0285(03)00115-4

Liikkanen, L. (2012). Musical activities predispose to involuntary musical imagery. Psychology of Music, 40(2), $236-256$. doi:10.1177/0305735611406578

Schulze, K., Mueller, K., \& Koelsch, S. (2011a). Neural correlates of strategy use during auditory working memory in musicians and non-musicians. The European Journal of Neuroscience, 33, 189-196. doi:10.1111/j.1460-9568.2010.07470.x

Schulze, K., Zysset, S., Mueller, K., Friederici, A. D., \& Koelsch, S. (2011b). Neuroarchitecture of verbal and tonal working memory in nonmusicians and musicians. Human Brain Mapping, 32, 771-783. doi:10.1002/hbm.21060

Williamson, V. J., Jilka, S. R., Fry, J., Finkel, S., Mullensiefen, D., \& Stewart, L. (2012). How do earworms start? Classifying the everyday circumstances of involuntary musical imagery. Psychology of Music, 40(3), 259-284. doi:10.1177/0305735611418553

Williamson, V. J., Baddeley, A., \& Hitch, G. J. (2010a). Musicians' and nonmusicians' short-term memory for verbal and musical sequences: Comparing phonological similarity and pitch proximity. [PubMed ]. Memory \& Cognition, 38(2), 163-175. doi:10.3758/MC.38.2.163

Williamson, V. J., McDonald, C., Deutsch, D., Griffiths, T., \& Stewart, L. (2010b). Faster decline of pitch memory over time in congenital amusia. Advances in Cognitive Psychology, 6, 15-22. doi:10.2478/v10053-008-0073-5

Williamson, V. J., Cocchini, G., \& Stewart, L. (2011). The relationship between pitch and space in congenital amusia. Brain and Cognition, 76(1), 70-76. doi:10.1016/j.bandc.2011.02.016 
Williamson, V. J., \& Stewart, L. (2010). Memory for pitch in congenital amusia: Beyond a fine-grained pitch perception problem. Memory (Hove, England), 18(6), 657-669. doi:10.1080/09658211.2010.501339 